\title{
Habit Forming: Voices from the Field
}

We presented a series of habits that highly effective restorationists might follow (Handel 2016), and asked readers to help by adding to the original list of seven. The submitted contributions fell into the categories of social, technical, and motivational. We are grateful for the many efforts of our contributors and wish to share these exceptional ones in the journal. - -The Editors

\section{Social Habits}

Habit 8. Build connections with special interest groups. By connecting with special interest groups there are many new avenues that can be taken. Many times these groups may help with funding for the project or just help give ideas of what can be done. They also may have large followings so more information can be relayed to the general population on restoration projects. When this happens, other people consider opportunities to start their own projects.

Seth Lapp

Goshen College, Indiana

Habit 9. Consult with local indigenous communities.

Listen to the voices of people with a true historic legacy of conservation. When it comes to a cultural connection with nature, European settler communities leave a lot to be desired. So our role is to collaborate and do so with humility (see Habits 1 and 5). Odds are, your restoration site is on land that was taken from native communities. Mine is. Learn whose land you occupy and what treaties were made on it. Connect with Native American communities and organizations in your region. Ask deep questions, and be prepared to be changed.

\section{Cecilia Lapp Stoltzfus Goshen College, Indiana}

Habit 10. Explore environmental justice implications. Remember that restoration can be a biased endeavor. We identify project sites, goals, and timelines based on our perceptions which may be plagued by racism and classism. So we must ask: How might this restoration be received by communities of color and local immigrant communities? Urban working class families? Is a rural site accessible and financially available to the poor urban public? Our work must inspire the next generation of culturally diverse restorationists.

Cecilia Lapp Stoltzfus Goshen College, Indiana

Ecological Restoration Vol. 35, No. 1, 2017

ISSN 1522-4740 E-ISSN 1543-4079

○2017 by the Board of Regents of the University of Wisconsin System.
Habit 11. Identify value systems.

From policy making in Washington DC to inspiring community involvement, social factors play a crucial role in restoration projects. However, differing values lead people to different ideas of what a restoration project should look like. Being mindful to identify the values from which people are basing their decisions will greatly aid effective communication and compromise in order to elicit restorative action.

\section{Grant Flaming Goshen College, Indiana}

Habit 12. Listen, avoid talking.

Spend $80 \%$ (or more) of your time listening to the concerns of others, so you can understand their concerns and issues that may affect your project. Careful listening will allow you to gather more information from others, so you will gain data to address their needs relative to the restoration project.

David Ross

NRDAR Restoration Support Unit Dept. of Interior, Denver, Colorado

\section{Technical Habits}

Habit 13. Play detective. Dust off the childhood magnifying glass.

Every place is full of secrets and mysteries. Hidden forces create every detail of landscapes. During restorations, every site has clues left by those forces to be uncovered, and there are endless mysteries to solve. When it comes to your land, always keep your eyes open for hints to new leads. By embracing the detective within and uncovering evidence for current conditions, we make positive decisions for restoration. However, just like narratives created by the criminal justice system, our narratives can never fully encompass reality.

\section{Hannah Thill Goshen College, Indiana}

Habit 14. Acknowledge the adaptability of nature Many of the most incredible aspects of the natural world come from organisms that survive in unlikely places and circumstances. Do everything you can to help these oddsdefying populations and habitats persist into the future. 
Act with optimism and purpose when you discover these survivors in your projects-even if they are unexpected or within an environment that is not the first candidate for restoration work.

\section{Isaac Godshalk Goshen College, Indiana}

\section{Motivational Habits}

\section{Habit 15. Have patience}

Ecological restoration is an ongoing process that truly never stops. One must have patience do deal with unexpected results, setbacks, and failures. Without patience, it would be very easy for someone to become frustrated, or to get tired of always having to keep working with the restoration project. Ecological restoration is not just a project that finishes and then you can marvel at it. Restoration is a never ending process, but with patience, one will find joys and beauty through the thick and thin.

Gabriel Eisenbeis Goshen College, Indiana

Habit 16. Remember the big picture

What's the point of restoring ecosystems to healthy structure, composition, and function in the first place? As you dig into the details of a project, it may be difficult to remember what your overarching goals were and why the project is valuable. Taking a moment now and then to just take a step back and breathe can help remind yourself of the myriad spiritual, scientific, educational, and moral reasons why it's worth years of work to restore the land. In tough and discouraging times, we need to find enough patience and grace to wake up the next morning and keep on keepin' on.

David Jantz San Diego, Colorado

Habit 17. Ask yourself why

While the process of self-inquiry seems only remotely relevant to the larger issues we face every day, it's important to bolster one's passion from the inside out-discover the fire within our own bellies even after so many years or decades of hard work for little pay. So why do we continue to do what we do? Because it matters that the planet's water, wind and wildlife thrive to the greatest degree possible. It makes the heart sing to tell people about the great work even tiny organizations are doing to make the natural world a better place. This long-term endeavor is about love, love for the planet, plain and simple.

Deb Merchant Marys River Watershed Council, Corvallis, Oregon

\section{Recommended Reading}

Handel, S.N. 2016. The Seven Habits of highly successful people who want to do ecological restoration. Ecological Restoration 34:171-172.

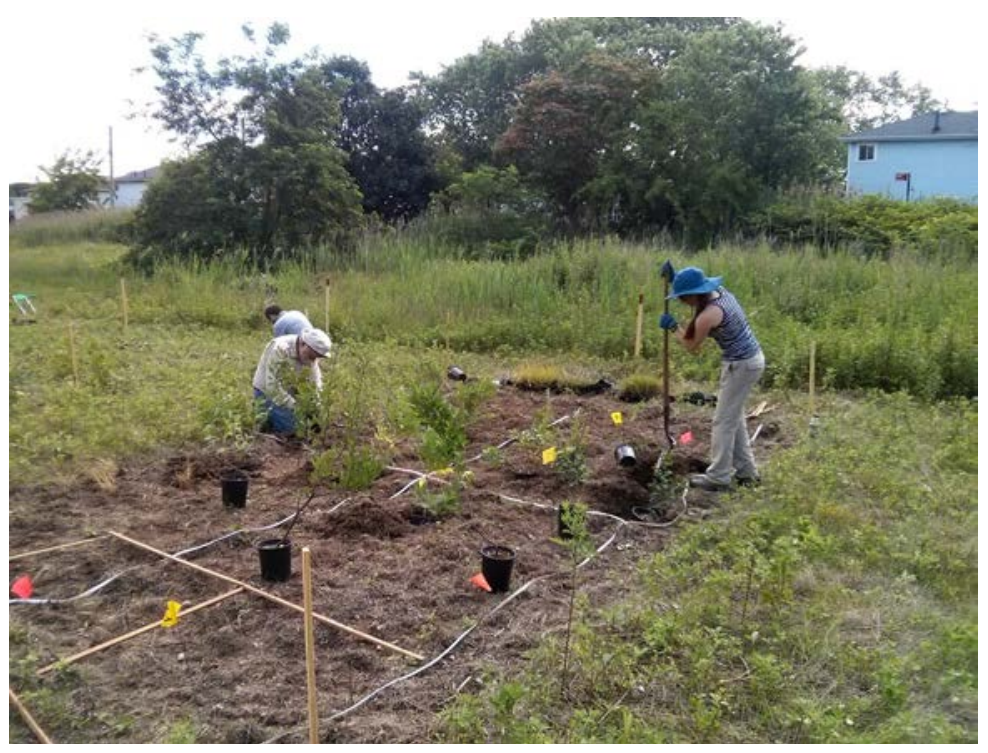

A seemingly idyllic scene, but every restoration project rests on integrating social, technical, and motivational skills. Photo credit: Jean Epiphan. 